\title{
Efisiensi Penggunaan Energi pada Lampu Penerangan Jalan Raya
}

\author{
Yuda Alferinanda ${ }^{1 *}$ Sari Ramadhani $^{1}$ dan Asnil ${ }^{1}$ \\ ${ }^{1}$ Jurusan Teknik Elektro FT UNP, Fakultas Teknik, Universitas Negeri Padang \\ "e-mail: yudaalferinanda75@yahoo.com
}

(Diterima: 20 Aprili 2020, direvisi: 17 Mei 2020, disetujui:30 Mei 2020)

\begin{abstract}
Abstrak
Penggunaan lampu jalan merupakan salah satu konsumsi energi yang besar dan masih belum efisien dalam penggunaannya. Untuk itu diperlukan sebuah sistem yang dapat mengontrol dan mengendalikan penggunaan energi pada lampu jalan agar penggunaan energi listrik menjadi lebih efisien. Pada penelitian ini, sistem yang dibangun adalah untuk mengendalikan penggunaan energi listrik pada lampu jalan menggunakan mikrokontroler Arduino Uno dengan memanfaatkan LDR (Light Dependent Resistor) dan PIR (Passive Infrared Receiver) sebagai sensor cahaya dan sebuah LCD untuk menampilkan jumlah kendaraan dan orang yang terdeteksi. Lampu jalan dirancang memiliki pencahayaan maksimal pada saat ada kendaraan atau pejalan kaki yang lewat dan akan redup jika sensor tidak ada mendeteksi pergerakan baik kendaraan atau orang yang lewat. Dari pengujian yang dilakukan, sistem dapat bekerja dengan baik sesuai dengan algoritma kerja yang dirancang.
\end{abstract}

Kata Kunci: Lampu Jalan, Arduino UNO, LDR, PIR, LCD

\section{Abstract}

The use of street lights is a big energy consumption and is still not efficient in its use. For that we need a system that can control and control the use of energy in street lights so that the use of electrical energy becomes more efficient. In this research, the system built is to control the use of electrical energy in street lights using an Arduino UNO microcontroller by utilizing LDR (Light Dependent Resistor) and PIR (Passive Infrared Receiver) as light sensors and an LCD to display the number of detected vehicles and people. Street lights are designed to have maximum lighting when there are vehicles or pedestrians passing by and will be dim if the sensor is not there to detect the movement of both vehicles or passersby. From the tests carried out, the system can work properly in accordance with the designed work algorithm.

Keywords: Street light, Arduino UNO, LDR, PIR, LCD 


\section{PENDAHULUAN}

Energi listrik merupakan salah satu energi yang sangat dibutuhkan dalam kehidupan. Di era modernisasi saat ini jumlah kebutuhan energi listrik di Indonesia cenderung meningkat. Salah satu pemakaian listrik yang banyak digunakan saat ini adalah sumber penerangan. Berdasarkan data kementerian ESDM, capaian konsumsi listrik pada 2019 baru sebesar $1.084 \mathrm{kWh}$ per kapita, adapun targetnya sebesar 1.200 kWh per kapita. Sementara itu, target konsumsi listrik pada tahun 2020 sebesar 1.142 $\mathrm{kWh}$ per kapita. Semakin meningkatnya tingkat mobilitas masyarakat membuat semua kegiatan memerlukan penerangan. Salah satu bagian yang terpenting dan memerlukan penerangan adalah jalan raya. Pada umumnya lampu jalan raya bekerja 12 jam perhari mulai dari pukul 18.00 sampai 06.00 WIB [1].

Perkembangan ilmu teknologi pada saat ini berkembang begitu pesat, secara keseluruhan aspek kehidupan manusia sangat tergantung pada teknologi. Dalam kehidupan sehari-hari, manusia menginginkan kemudahan dalam beraktivitas atau pekerjaan akhirnya muncul ide-ide kreatif untuk membuat sebuah alat yang sederhana dan ramah lingkungan yang bisa berguna bagi banyak orang. Contohnya seperti lampu jalan otomatis [2]. Sistem kerja pada lampu jalan otomatis ini dikontrol oleh sebuah mikrokontroller yaitu arduino uno serta menggunakan sensor LDR (Light Dependent Resistor) dan sensor PIR (Passive Infrared Receiver). Sensor LDR akan bekerja apabila terdeteksi intensitas cahaya yang diproses oleh mikrokontroler arduino uno sedangkan sensor PIR akan bekerja jika mendeteksi pergerakan yang diproses oleh mikrokontroler arduino uno. Ketika keadaan intensitas cahaya matahari menurun mencapai batas tertentu atau gelap karena malam maka lampu akan secara otomatis menyala redup, jika terdeteksi ada kendaraan atau seseorang yang melewati jalan tersebut maka lampu akan menyala terang. Jika tidak ada pergerakan dari manusia maka lampu akan kembali redup namun ketika keadaan sudah pagi dan terang karena adanya sinar matahari, maka lampu otomatis padam atau mati [3].

\section{Arduino Uno}

Salah satu kit mikrokontroler yang berbasis pada ATmega28. Memiliki 14 pin digital input/output, 6 analog input, sebuah resonator keramik 16MHz, koneksi USB, colokan power input, ICSP header, dan sebuah tombol reset [4].

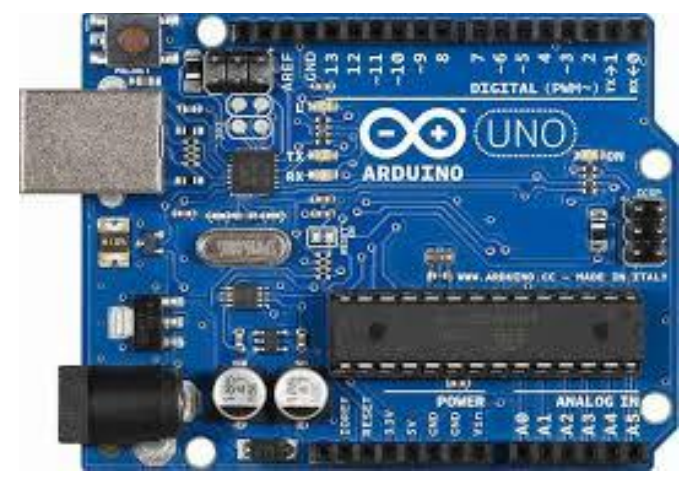

Gambar 1 Arduino Uno 


\section{Baterei Lithium-ion}

Baterai lithium seperti gambar 2, secara teori adalah baterai yang digerakkan oleh ion lithium. Dalam kondisi discharge dan recharge baterai lithium bekerja menurut fenomena interkalasi, dimana ion lithium melakukan migrasi dari katoda lewat elektrolit ke anoda atau sebaliknya tanpa terjadi perubahan struktur kristal dari bahan katoda dan anoda [5]

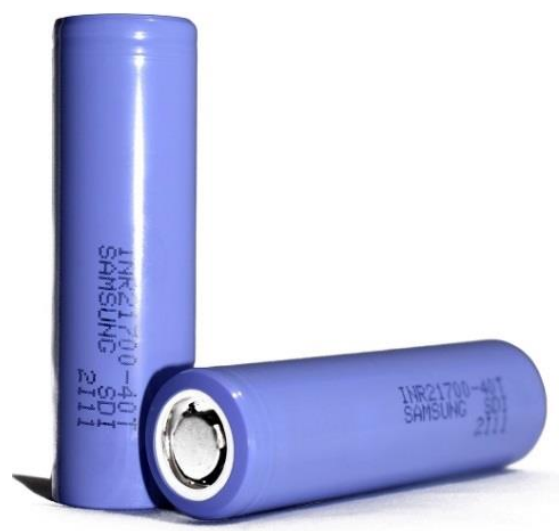

Gambar 2 Baterai Lithium-Ion

\section{Sensor Light Dependent Resistor (LDR)}

Light Dependent Resistor (LDR) ialah jenis resistor yang berubah hambatannya karena pengaruh cahaya. Besarnya nilai hambatan pada sensor cahaya LDR tergantung pada besar kecilnya cahaya yang diterima oleh LDR itu sendiri. Bila cahaya gelap nilai tahanannya semakin besar, sedangkan cahayanya terang nilainya menjadi semakin kecil [6]. LDR akan bekerja Jika intensitas cahaya yang diterima tinggi maka hambatan juga akan tinggi yang mengakibatkan tegangan yang keluar juga akan tinggi begitu juga sebaliknya disinilah mekanisme proses perubahan cahaya menjadi listrik terjadi [7].
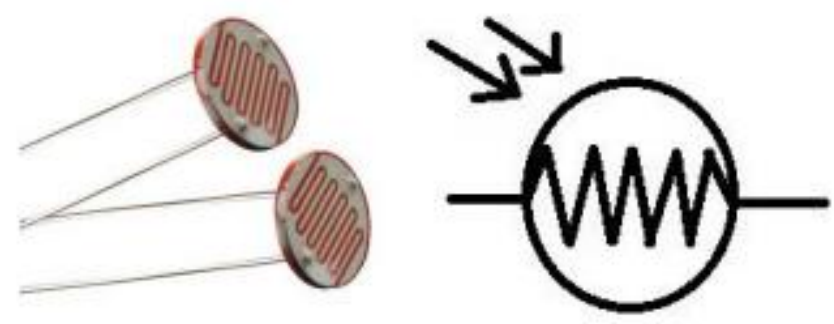

Gambar 3 Bentuk Fisik dan Simbol LDR

\section{Sensor Passive Infrared Receiver (PIR)}

Sensor Passive Infrared Receiver (PIR) adalah sensor yang digunakan untuk mendeteksi adanya pancaran sinar infra merah. Sensor PIR bersifat pasif, artinya sensor ini tidak memancarkan sinar infra merah tetapi hanya menerima radiasi sinar infra merah dari luar [8]. 


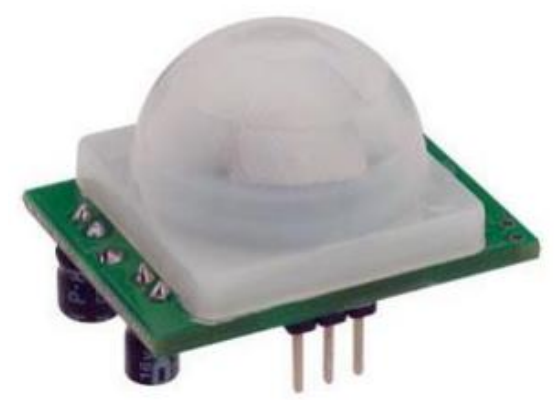

Gambar 4 Bentuk Fisik Sensor PIR

\section{High Power LED (HPL)}

Light Emitting Diode atau sering disingkat dengan LED adalah komponen elektronika yang dapat memancarkan cahaya monokromatik ketika diberikan tegangan maju. LED merupakan keluarga dioda yang terbuat dari bahan semikonductor. Warnawarna cahaya yang dipancarkan oleh LED tergantung pada jenis bahan semiconductor yang dipergunakannya. High Power LED (HPL) memproduksi intensitas cahaya lampu yang lebih kuat, atau bisa disebut yang paling kuat di antara semua jenis lampu LED [9].

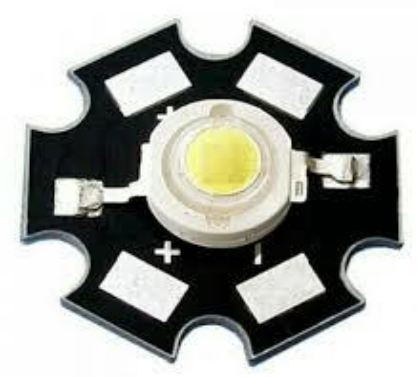

Gambar 5. High Power LED

\section{Liquid Crystal Display (LCD) 20x4 dengan I2C}

Liquid Crystal Display (LCD) adalah perangkat yang berfungsi sebagai media penampil dengan memanfaatkan kristal cair sebagai objek penampil utama. LCD tentunya sudah sangat banyak digunakan untuk berbagai macam keperluan seperti media elektronik televisi, kalkulator, atau layar komputer sekalipun [10].

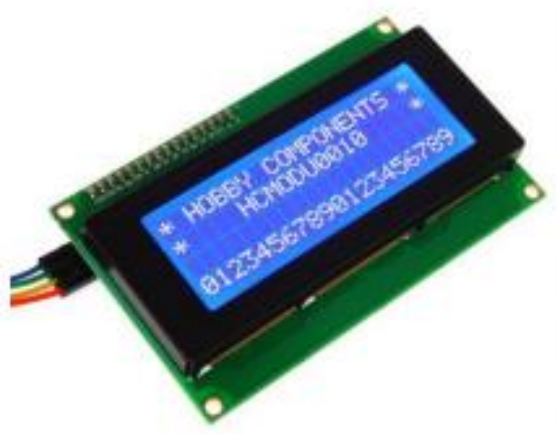

Gambar 6. Bentuk Fisik LCD 


\section{Arduino IDE}

Aplikasi Arduino IDE berfungsi untuk membuat, membuka, dan mengedit program yang akan kita masukkan ke dalam board Arduino. Aplikasi Arduino IDE dirancang agar memudahkan penggunanya dalam membuat berbagai aplikasi. Arduino IDE memiliki struktur bahasa pemrograman yang sederhana dan fungsi yang lengkap, sehingga mudah untuk dipelajari oleh pemula sekalipun [11].

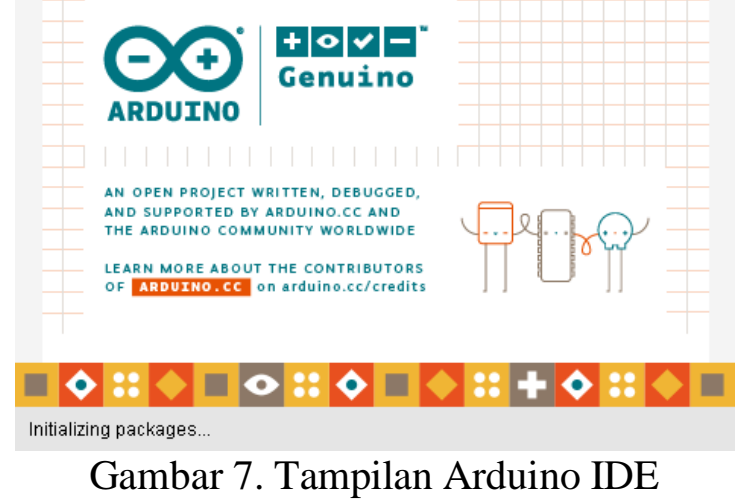

\section{METODE}

Metode ini berupa rancang bangun sistem lampu jalan otomatis berbasis arduino uno. Perangkat mekaniknya terdiri dari Arduino Uno, Baterai 18650, IC Regulator 7805, LCD (Liquid Crystal Display), Sensor PIR (Passive InfraRed), Sensor LDR (Light Dependent Resistor), LED HPL (High Power LED).

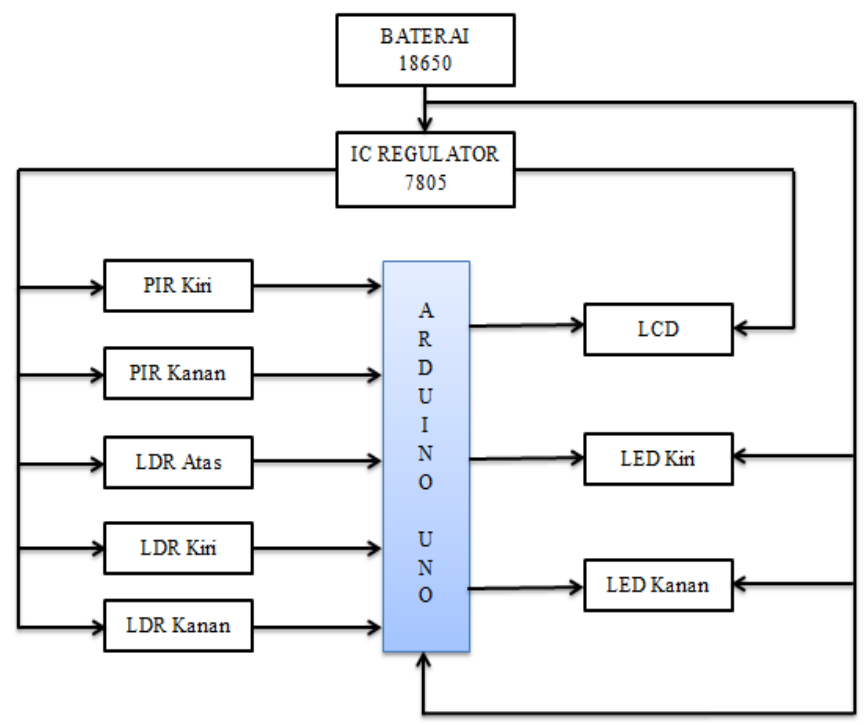

Gambar 8. Blok Diagram Lampu Jalan Otomatis

Gambar 8 merupakan blok diagram dari rancang bangun sistem lampu jalan otomatis, berikut fungsi masing-masingnya.

1. Arduino uno merupakan pusat pengontrolan kerja alat, arduino menerima data sensor dan mengolah data tersebut sesuai dengan keluaran yang diinginkan.

2. Baterai jenis 18650 merupakan sumber listrik yang akan digunakan.

3. IC regulator 7805 berfungsi untuk mengatur tegangan output stabil pada tegangan 5 Volt. 
4. LCD berfungsi untuk menampilkan jumlah mobil dan orang yang lewat.

5. Sensor PIR kiri dan sensor PIR kanan berfungsi untuk menangkap pancaran sinyal infra merah yang dipancarkan oleh suhu tubuh manusia atau hewan.

6. LDR atas merupakan sensor yang sangat peka terhadap cahaya. Apabila keadaan mulai gelap atau matahari mulai terbenam sensor ini akan otomatis menghidupkan LED (menyala redup).

7. LDR kiri dan LDR kanan merupakan sensor yang akan bekerja apabila sensor tersebut terkena cahaya lampu dari kendaraan yang melalui jalan tersebut baik jalur kiri maupun jalur kanan.

8. LED HPL (High Power LED) merupakan output dari sensor LDR maupun sensor PIR. Intensitas LED ini diatur oleh Pulse Width Modulation atau PWM. Jika sensor LDR atas tidak terkena cahaya (keadaan gelap) maka nilai PWM 50\%. Apabila LDR Kiri dan LDR Kanan mendeteksi cahaya kendaraan maka nilai PWM akan mencapai $100 \%$.

Flowchart dari sistem ang dibuat dapat dilihat pada gambar 9 yang berfungsi sebagai acuan dalam membuat listing program serta berisi penentuan instruksi dari program yang akan dibuat.

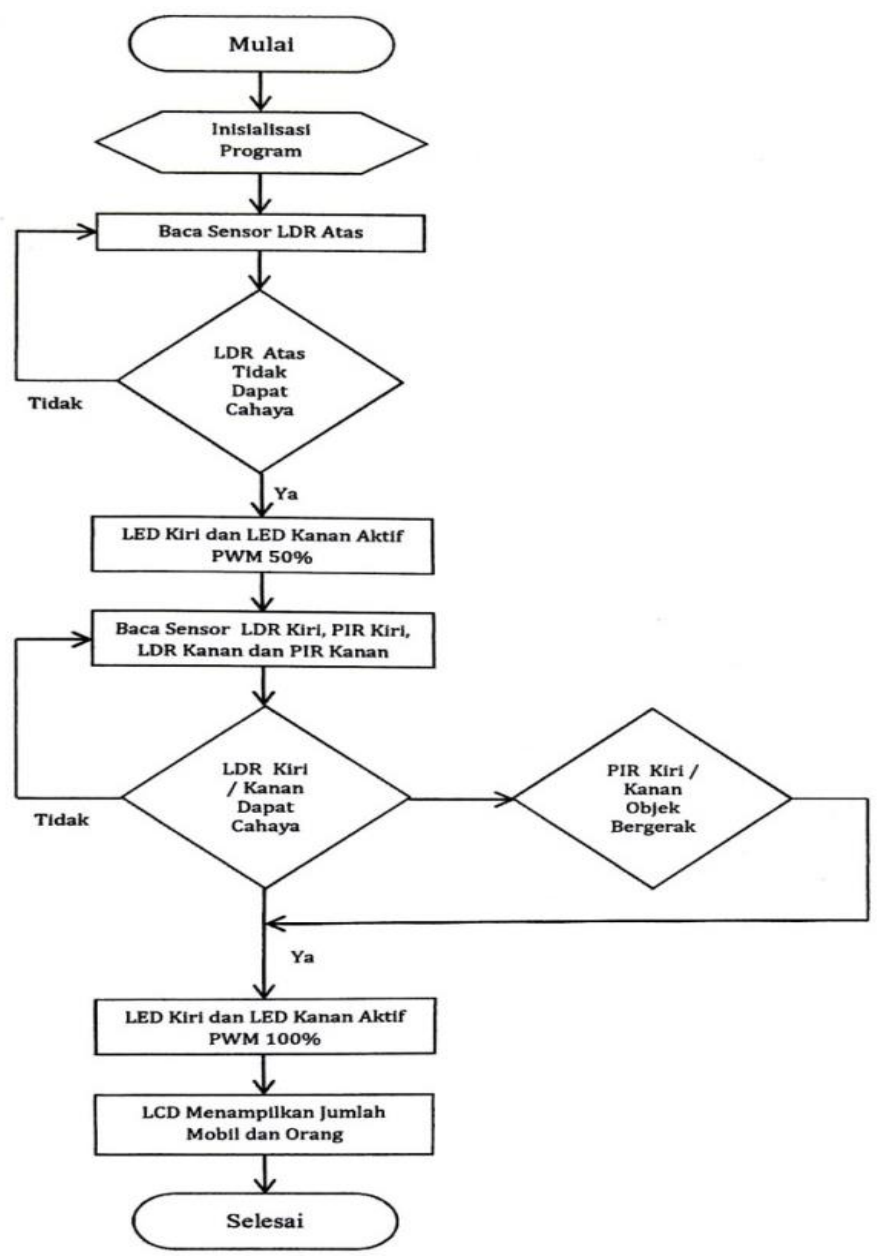

Gambar 9. Flowchart Lampu Jalan Otomatis 


\section{HASIL DAN PEMBAHASAN}

\section{Konfigurasi Program}

Konfigurasi adalah tahap awal dari pemrograman yang diawali dengan konfigurasi berkas library untuk Arduino Uno seperti pada gambar 10.

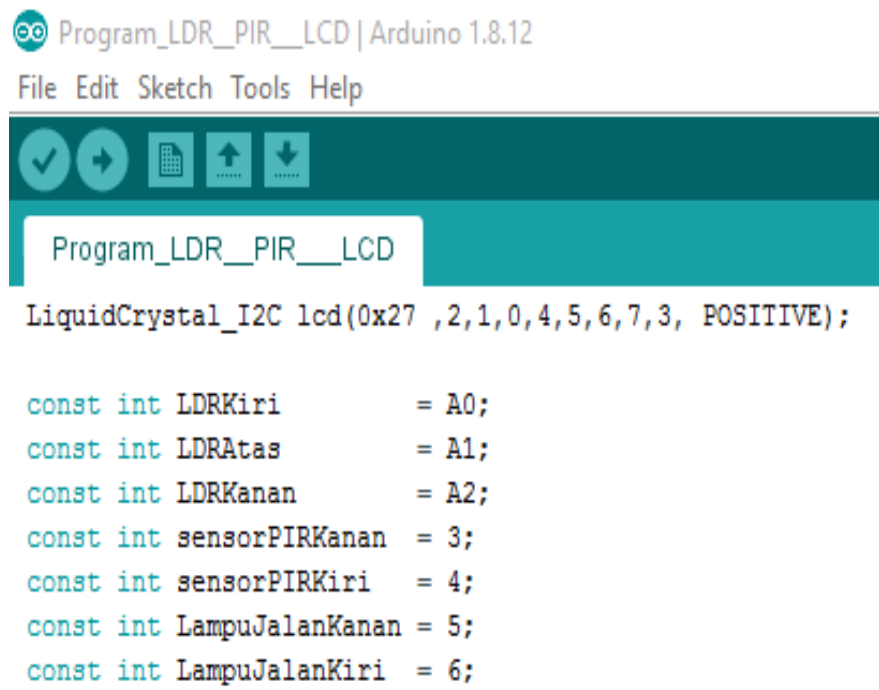

Gambar 10. Konfigurasi Awal Program

Pada gambar 10 dapat dijelaskan Pin yang digunakan sebagai input adalah LDR Kiri pada pin analog A0, LDR Atas pada pin analog A1, LDR Kanan pada pin analog A2, sensor PIR Kanan pada pin digital 3 dan sensor PIR Kiri pada pin digital 4. Sedangkan Pin yang digunakan sebagai output adalah Lampu Jalan Kanan pada pin digital 5, Lampu Jalan Kiri pada pin digital 6 dan untuk LCDnya digunakan pin scl dan sda.

\section{Pengujian Sensor LDR}

Program sensor untuk LDR dapat dilihat pada gambar 11, dengan menggunakan pin analog pada Arduino untuk pembacaan ADC.

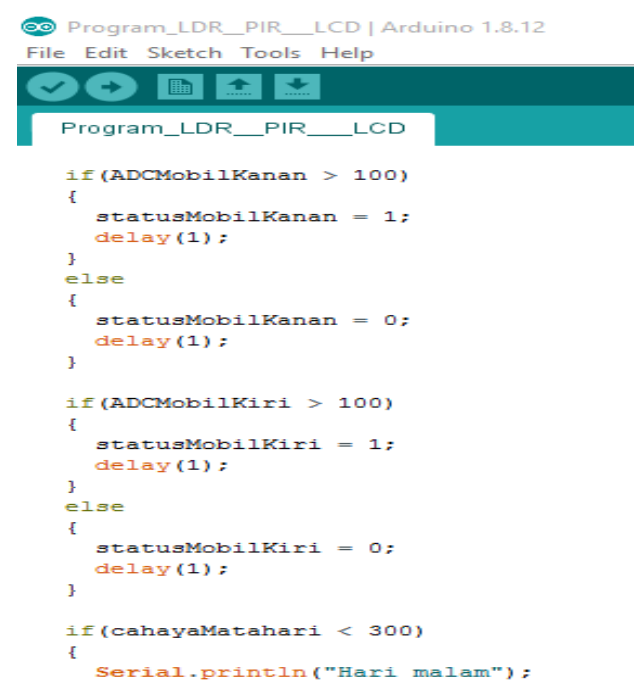

Gambar 11. Program Sensor LDR 
Ketika nilai ADC < 300 maka LDR Atas akan aktif yang akan menghidupkan LED Kiri dan LED Kanan menyala redup (Nilai ADC 255). Untuk mengaktifkan LDR Kiri dan LDR Kanan nilai ADCnya yaitu > 100 pada saat LDR mendapatkan cahaya maka LED Kiri dan LED Kanan akan menyala terang.

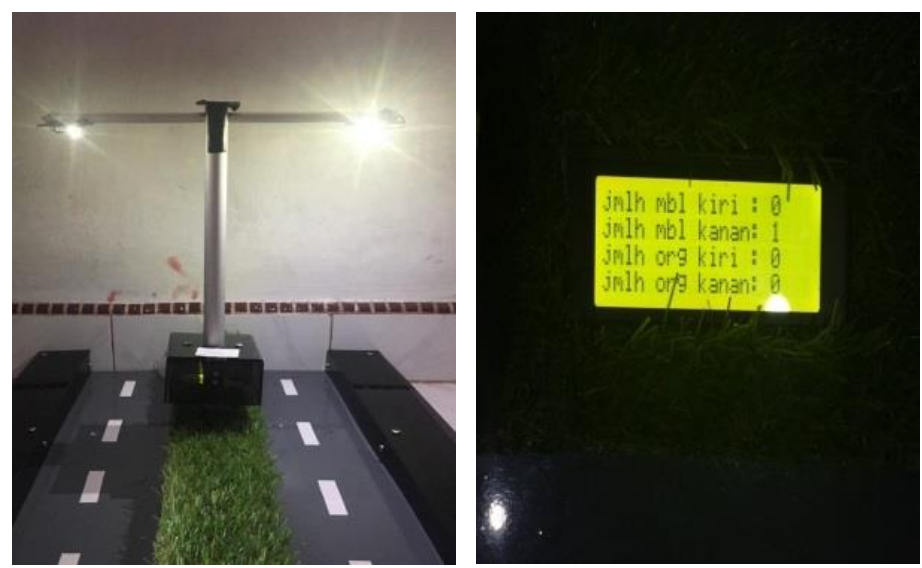

Gambar 12. Hasil Pengujian Sensor LDR Kanan
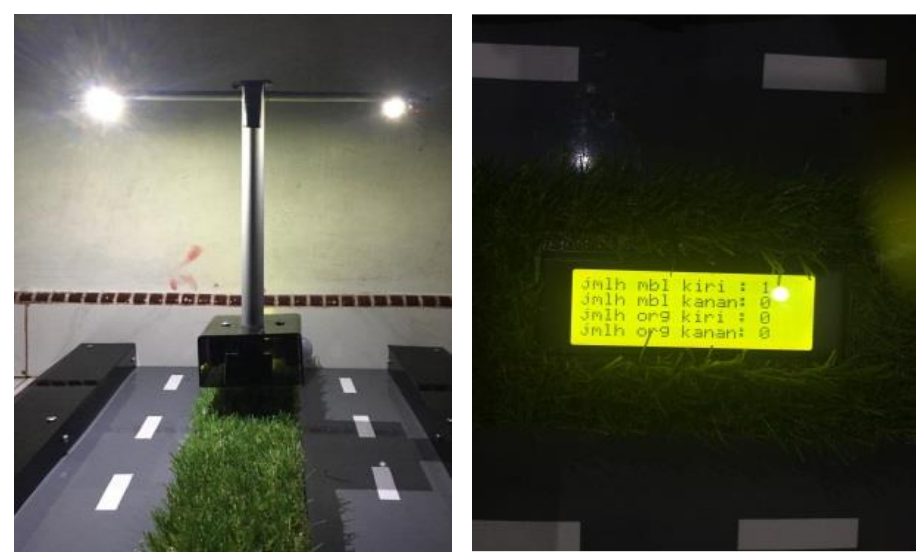

Gambar 13. Hasil Pengujian Sensor LDR Kiri

\section{Pengujian Sensor PIR}

Pada gambar 14 merupakan pemrograman sensor PIR untuk menghidupkan lampu menyala terang dapat dilakukan berdasarkan pergerakan manusia. Ketika sensor PIR Kiri ataupun PIR Kanan mendeteksi adanya gerakan (bernilai logika 1), maka lampu yang tadinya redup akan menyala terang. 


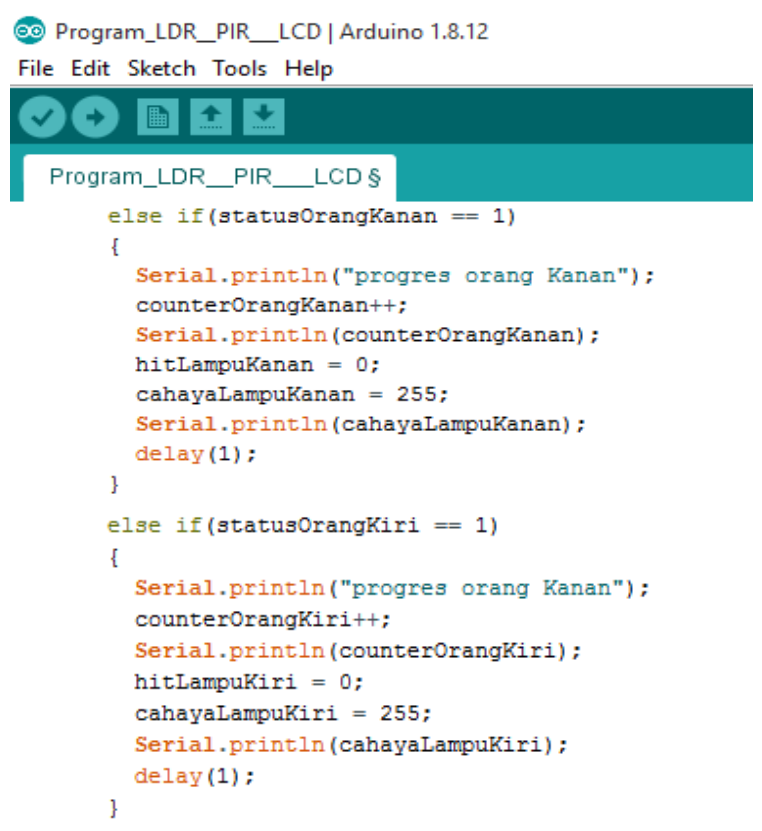

\section{Gambar 14. Program sensor PIR}

Gambar 15 adalah hasil pengujian sensor PIR, dimana terlihat salah sau lampu yang terhubung ke sensor PIR terlihat terang maksimal dan lampu lain redup. Begitu juga dengan gambar 16 yang bergantian mendeteksi adanya pergerakan dan hasil perhitungan atau jumlah pergerakan yang dideteksi oleh sensor ditampilkan pada LCD.
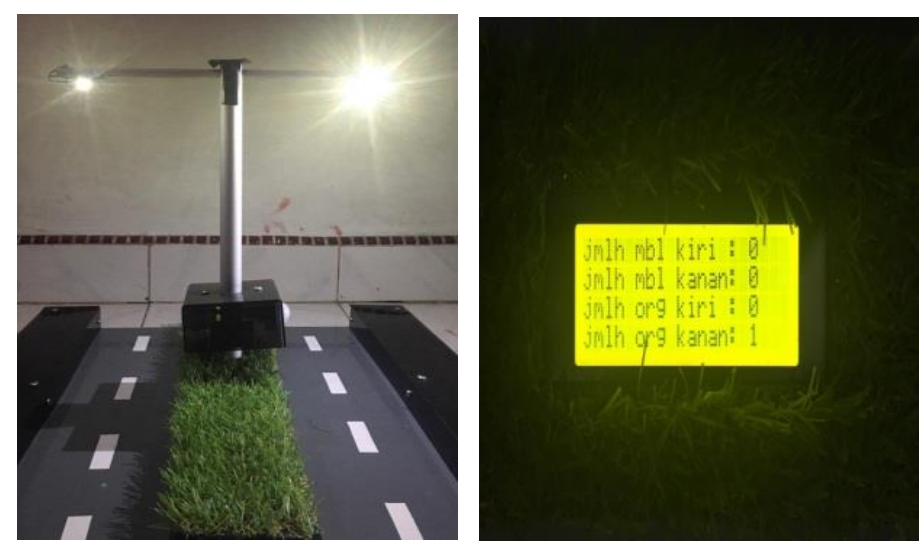

Gambar 15. Hasil Pengujian Program Sensor PIR Kanan
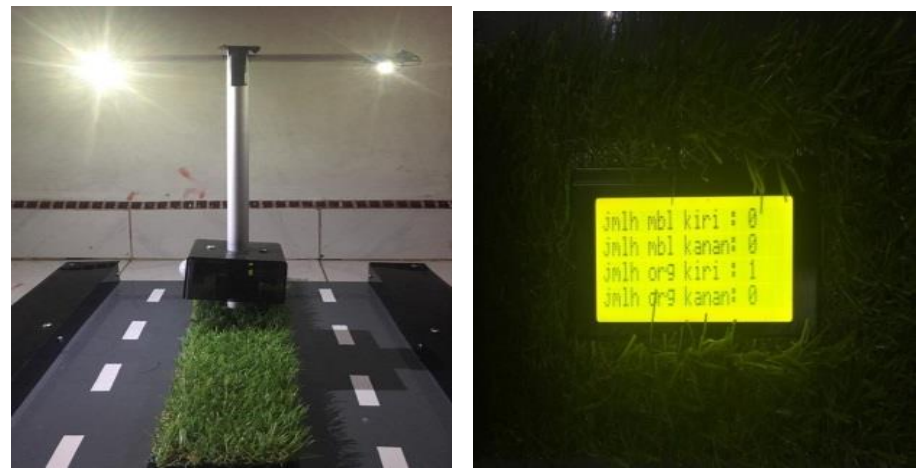

Gambar 16. Hasil Pengujian Program Sensor PIR Kiri 


\section{Pengujian LCD}

Berikut ini merupakan program dari tampilan jumlah mobil dan jumlah orang yang mengaktifkan LCD 4 baris x 20 karakter.

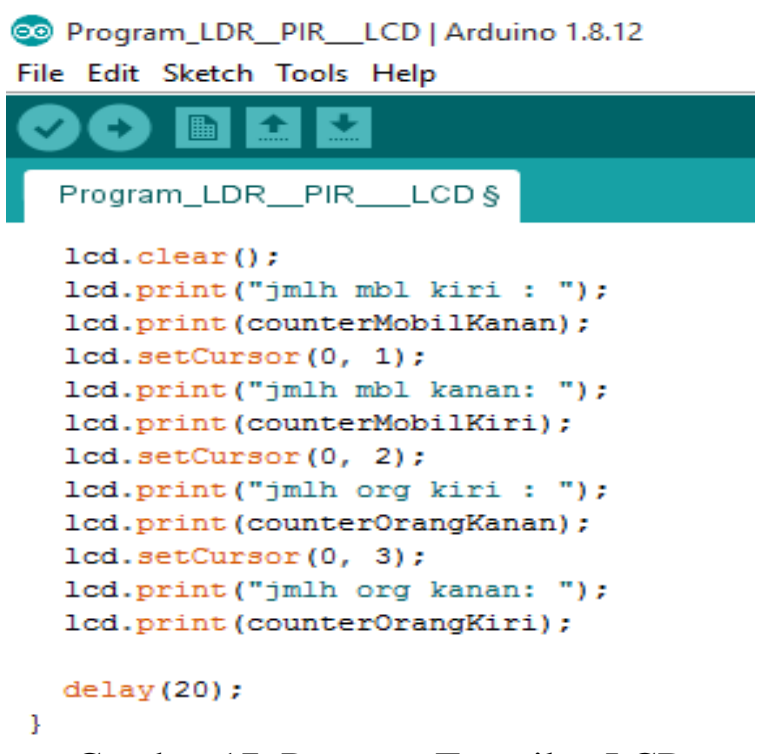

Gambar 17. Program Tampilan LCD

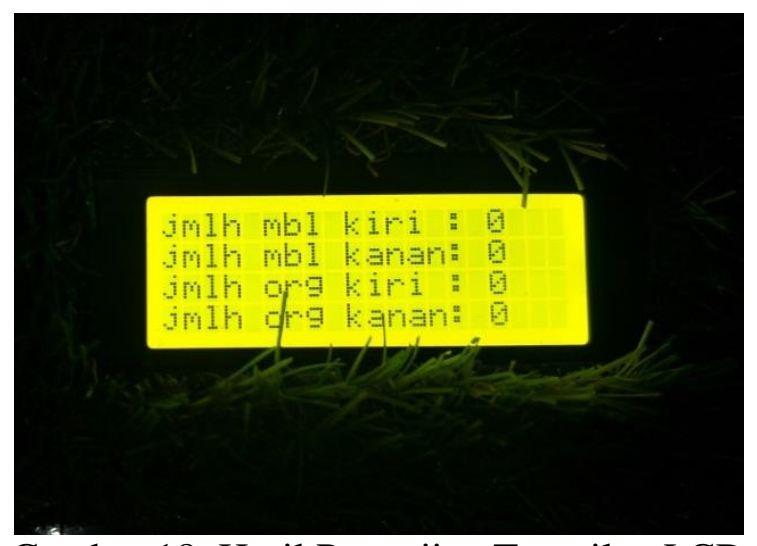

Gambar 18. Hasil Pengujian Tampilan LCD

Gambar 18 adalah bentuk tampilan LCD yang menampilkan jumlah perhitungan kendaraan arau orang yang lewat yang terdeteksi oleh sensor.

\section{SIMPULAN DAN SARAN}

\section{Simpulan}

Berdasarkan hasil pengujian dan pembahasan pada pemograman sistem lampu jalan otomatis berbasis arduino uno dapat disimpulkan bahwa lampu jalan otomatis menyala dan padam sesuai dengan pembacaan sensor cahaya (LDR) dan sensor gerak (PIR) ditunjukkan pada hasil pengujian.

\section{Saran}

Setelah melakukan pengujian, pengukuran dan pembahasan terhadap kinerja dari alat lampu jalan otomatis berbasis arduino uno, maka ada saran yang diberikan penulis 
untuk kesempurnaan alat ini yaitu pengaplikasiannya sebaiknya menambahkan sensor lainnya seperti sensor pendeteksi suhu tubuh dan lain sebagainya.

\section{REFERENSI}

[1] “PENDAHULUAN LAMPU JALAN OTOMATIS,” pp. 1-4.

[2] T. Firmansyah, "Rancang Bangun Sistem Penerangan Jalan Umum ( Pju ) Otomatis Menggunakan Passive Infrared Sensor," no. December, 2018.

[3] Nanda Epriliana Asmara Putri, "PROJECT SENSOR DAN TRANDUSER LAMPU JALAN OTOMATIS,” 2018.

[4] Politeknik Negeri Sriwijaya, "Pada Tabel 2.1 berikut menampilkan Senyawa Semikonduktor yang digunakan untuk menghasilkan variasi warna pada LED :," pp. 5-32.

[5] B. A. B. Ii, “discharge dan recharge,” pp. 6-19.

[6] B. A. B. Ii and T. Pustaka, "LDR digunakan untuk mengubah energi cahaya menjadi energi listrik. Saklar cahaya otomatis dan alarm pencuri adalah beberapa contoh alat yang 6," pp. 6-32.

[7] W. Purba, "Lampu Jalan Hemat Energi Otomatis Berbasis Mikrokontroler Arduino Uno," 2019.

[8] Hermawati, "Bab Ii Landasan Teori," J. Chem. Inf. Model., vol. 53, no. 9, pp. 1689-1699, 2013, doi: 10.1017/CBO9781107415324.004.

[9] P. D. Sugiyono, "High Power LED," J. Chem. Inf. Model., vol. 53, no. 9, pp. 1689-1699, 2016, doi: 10.1017/CBO9781107415324.004.

[10] L. S. B. A. \& Wolfman, "LCD $20 \times 4$ (Liquid Crystal Display) dengan I2C LCD,” J. Chem. Inf. Model., vol. 53, no. 9, pp. 1689-1699, 2013, doi: 10.1017/CBO9781107415324.004.

[11] Junaidi and Y. D. Prabowo, Project Sistem Kendali Elektronik Berbasis Arduino. 2018. 
